

XVII Congresso Internacional sobre Patologia e

Reabilitação das Construções

XVII Congreso Internacional sobre Patología y Rehabilitación de las Construcciones

XVII International Conference on Pathology and Constructions Rehabilitation

FORTALEZA (Brasil), 3 a 5 de junho de 2021

https://doi.org/10.4322/CINPAR.2021.067

\title{
Análise Termo-Higrométricas Da Catedral Nossa Senhora Das Mercês E Suas Implicações Nas Manifestações Patológicas.
}

\section{Thermo-Hygrometric Analysis Of Our Lady Of Merces Cathedral And Its Implications In Pathological Manifestations.}

\author{
Jackeline Maria Macedo ${ }^{1}$, Douglas Freitas Augusto dos Santos ${ }^{2}$ \\ ${ }^{1}$ Instituto Tocantinense Presidente Antônio Carlos, Porto Nacional - TO, Brasil, jackelinemmaria@hotmail.com \\ ${ }^{2}$ Instituto Tocantinense Presidente Antônio Carlos, Porto Nacional - TO, Brasil, eng.prof.santos@gmail.com
}

Resumo: $O$ adobe é uma técnica construtiva que foi bastante utilizada no século XVI. É constituído de solo, água, fibras e/ou adições, possuindo baixa resistência a água e aos efeitos térmicos, essa técnica construtiva é mais indicada para regiões secas. Com o desenvolvimento tecnológico na construção civil o uso habitual do adobe foi reduzido, cedendo espaço aos materiais industrializados. No entanto, em algumas cidades podese encontrar estruturas históricas com a utilização do adobe, como é o caso da Catedral Nossa Senhora das Mercês em Porto Nacional no estado do Tocantins. A Catedral foi construída no ano de 1894 e possui um sistema misto de adobe e pedra. O presente trabalho analisou o comportamento térmico e de umidade relativa da Catedral, por intermédio de medidores de temperatura e através de software Revit, adotando assim o conceito de Heritage BIM (H-BIM). Diante disso, foi possivel constatar os impactos e manifestações patológicas que o efeito da temperatura e umidade relativa do ar tem causado na estrutura da Catedral.

Palavras-chave: Patrimônio Histórico. H-BIM. Manifestações Patológicas

ABSTRACT: Adobe is a constructive technique that was widely used in the 16th century. It consists of soil, water, fibers and/or additions, having low resistance to water and thermal effects, this constructive technique is more suitable for dry regions. With the technological development in civil construction, the habitual use of adobe was reduced, giving space to industrialized materials. However, in some cities you can find historic structures with the use of adobe, as is the case of the Our Lady of Merces Cathedral in Porto Nacional in the state of Tocantins. The Cathedral was built in 1894 and has a mixed system of adobe and stone. The present work analyzed the thermal and relative humidity behavior of the Cathedral, through temperature meters and through Revit software, thus adopting the concept of Heritage BIM (H-BIM). Therefore, it was possible to verify the impacts and pathological manifestations that the effect of temperature and relative humidity of the air has caused on the structure of the Cathedral.

Keywords: Histrocial Heritage, H-BIM, Pathologial Manifestations.

\section{Introdução}

A igreja Catedral Nossa Senhora das Mercês é uma igreja tombada, situada em Porto Nacional no Estado do Tocantins, composta de pedra e adobe. $O$ adobe é uma técnica construtiva que foi bastante utilizada durante séculos, possuindo em sua composição terra em estado plástico, água, palhas ou outras fibras naturais. As estruturas compostas por adobe sobreviveram durante anos, o solo foi um dos primeiros materiais moldados pelo homem, pois é uma matéria prima abundante e de fácil acesso. A pedra é um bem natural, que possui elevada durabilidade e resistência. É comum encontrar estruturas em pedras, principalmente em cidades históricas integrando edificações como as igrejas, castelos, monumentos, esculturas, pontes, entre outros. É 
comum verificar em estruturas de adobe a utilização de pedras como infraestrutura e base para a estrutura, a fim de gerar maior durabilidade do adobe devido o contato com o solo.

Um ponto importante a se destacar é a compreensão da duração e o comportamento desses materiais em relação a variação da temperatura. No Brasil, as principais regiões que se encontram estruturas compostas por adobe são as regiões com climas quentes e secos como é o caso do norte e o nordeste. Os principais materiais utilizados para a fabricação do adobe são o solo e a água, o mesmo possui um comportamento térmico diferente por regiões e assim é indicado para regiões de clima seco e que possuem um baixo índice pluviométrico. As alvenarias de pedras também variam o seu comportamento, entrentanto devido ao seu grande centro de massa elas são mais resistentes a variação de temperatura. Para tanto, é primordial o estudo do comportamento desses materiais para diagnosticar as causas do aparecimento de manifestações patólogicas, desta forma auxiliar na conservação e renovação de um patrimônio cultural. Desta forma, objetiva-se compreender o comportamento termo-higrométricas da Catedral Nossa Senhora das Mercês. Localizada em Porto Nacional no Tocantins, a Catedral Nossa Senhora das Mercês é um monumento histórico, constituída por um sistema misto de pedra e adobe, englobando um estilo românico de Toulouse na França (IPHAN, 2018). A Figura 1 retrata a imagem frontal da Catedral.



Figura 1 - Catedral Nossa Senhora das Mercês

A Catedral Nossa Senhora das Mercês foi construída em 1894. Atualmente é um dos principais pontos turísticos de Porto Nacional. Na construção da catedral foram utilizados pedras e tijolos de adobe assentados com argamassa de cinza, areia e água. Foi utilizado arenito na base da estrutura e rocha sedimentar. Empregando técnicas de construção do período colonial na parte superior da estrutura, foi usado tijolos de barro de alta resistência e pedra canga. A fundação possui mais de dois metros de profundidade, os pilares internos são integrados de pedras emparelhadas obtendo uma maior rigidez. As construções em adobe não necessitavam de revestimento, dessa forma, a fachada da igreja conservava um estilo românico (MANDUCA, 2007; OLIVEIRA, 1997).

$\mathrm{O}$ adobe tem como composto fundamental a terra. A terra é um material que tem como característica a regulagem da umidade ambiental, o barro possui a habilidade de absorver e perder a umidade de maneira rápida comparado aos outros materiais de construção. Outra característica da terra é o armazenamento do calor, o que também ocorre em outros materiais densos como as alvenarias de pedra, durante a exposição do barro aos raios solares ele armazena calor e perde lentamente quando há mudanças de temperatura (PISANI, 2013).

Uma importante observação em construções feitas com terra é que dependendo das características geológicas e climáticas da região pode variar a sua composição quanto a resistência mecânica, textura, coloração e comportamento estrutural. Outro fator a ser considerado é a permeabilidade das construções de terra, pois são afetadas com as águas, sejam pluviais, do solo ou de instalações. Uma das principais causas de patologias nas construções feitas de adobe é a presença de água e a deficiência do planejamento das fundações, o que gera uma ação direta ou indireta em quase todos os tipos de problemas estruturais (VARUM et al., 2008).

A estabilidade dos blocos de pedras é normal e adequada, possuindo uma relação com as ações das chuvas, vento e poeiras, assim como as ações dos agentes químicos e orgânicos dos materiais e dos solos. Porém, 
atualmente existem algumas ações que estão interferindo na duração desse material, como as chuvas ácidas. Por outro lado, essas ações variam em função do tipo de pedra e da região, pois dependem dos fatores climáticos, físicos, químicos e microbiológicos. Então, para se obter alvenarias de pedras duradouras, devem possuir como características boa resistência a compressão, serem duras, compactas, não possuir argilas, não possuir impurezas como poeiras, terras e vegetais. No processo construtivo, devem ser regulares e bem aparelhadas, além de serem dispostas para que possam receber as cargas verticais (BRITO e FLORES, 2003). Apesar do seu extenso emprego no exterior e crescente no Brasil, para o projeto e gerenciamento da vida útil de novas edificações, pouca pesquisa tem sido desenvolvida para explorar tecnologias de BIM no gerenciamento do patrimônio histórico. O Historic Building Information Modeling (H-BIM) nada mais é que a extensão do conceito BIM para as edificações históricas e visa a documentação, a análise e a conservação de edifícios históricos. Segundo DORE E MURPHY (2012), o H-BIM contempla um processo que envolve uma solução de engenharia reversa onde, inicialmente, os elementos arquitetônicos são mapeados usando varredura a laser ou fotogrametria. Em seguida, os dados levantados são combinados a objetos paramétricos, gerando o modelo completo.

\section{Metodologia}

Para realizar o estudo, foi medido as temperaturas da Catedral Nossa senhora das Mercês nas laterais externas da estrutura. As distâncias para obter as temperaturas nas laterais foram definidas através da parte frontal, com o auxílio de uma trena, obtendo as distâncias de 10, 15 e 20 metros, como exemplifica a figura 4.

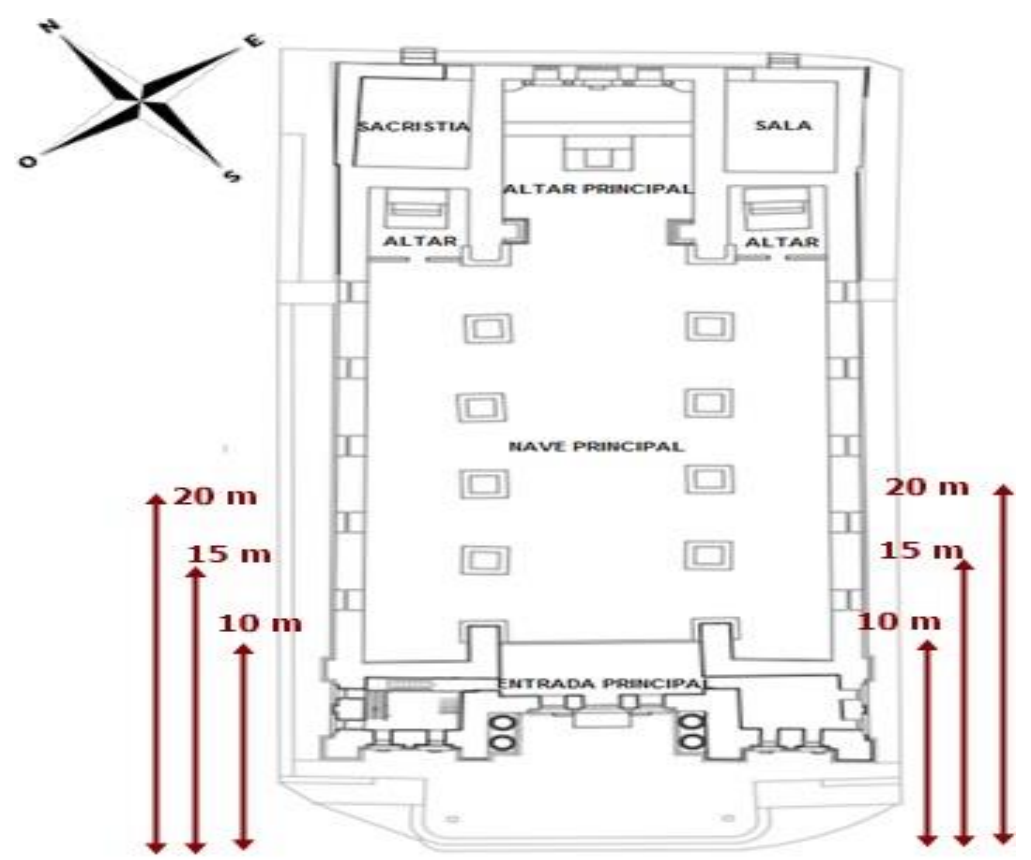

Figura 4 - Distâncias para as medidas

As temperaturas externas foram medidas através do termômetro infravermelho (Figura 5). Para isto, foram escolhidas as alturas de $30 \mathrm{~cm}, 2$ metros, 3 metros e 7 metros. As medições ocorreram em 3 horários distintos, sendo eles, matutino, vespertino e noturno, cada temperatura foi medida 3 vezes e após foi calculado a média diária, também foram utilizadas as maiores e as menores temperaturas para cada horário e para cada vista, além da média diária. Estas medições serviram como comparativo as obtidas pelo Revit através do Green Building Studio.

Após obter os valores necessários das temperaturas, foi iniciado o projeto arquitetônico no software Revit 2020. A edificação foi detalhada para apresentar características mais realistas possíveis, os parâmetros dos materiais adobe e pedra. 
Com o modelo arquitetônico e os parâmteros dos materiais atribuidos, foi empregado os valores das temperaturas com base na estação meteorológica integrada ao Revit de acordo com a localização especificada. E após esta etapa foi realizado no Green Building Studio as análises.

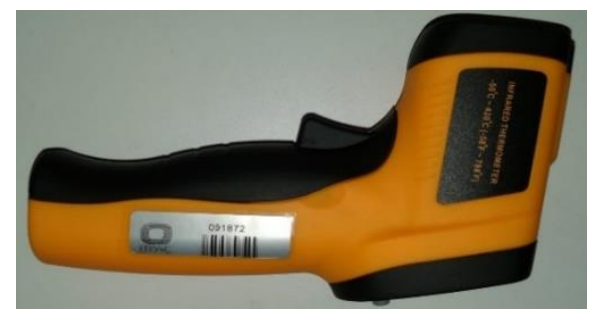

Figura 5 - Termômetro Infravermelho

No Quadro 1 é apresentado os valores adotados que foram necessários para a análise. Algumas das informações foram certificadas através dos autores Tagomori e Cavallaro (2011), Pereira (2008), Zinganoi, Koppeil e Costa (2006), Vallejo (2002) e Souza (2010).

Quadro 1 - Propriedades térmica e mecânica do adobe e do arenito.

\begin{tabular}{|c|c|c|c|c|c|}
\hline \multirow{2}{*}{\multicolumn{2}{|c|}{$\begin{array}{c}\text { Adobe } \\
\text { Térmico }\end{array}$}} & \multicolumn{4}{|c|}{ Arenito } \\
\hline & & \multicolumn{2}{|c|}{ Mecânica } & \multicolumn{2}{|c|}{ Térmico } \\
\hline $\begin{array}{l}\text { Condutividade } \\
\text { Térmica }\end{array}$ & $0,5200 \mathrm{w} /(\mathrm{m} \cdot \mathrm{k})$ & Modulo Young & $\begin{array}{l}55.000,0 \\
\mathrm{MPa}\end{array}$ & $\begin{array}{l}\text { Condutividade } \\
\text { Térmica }\end{array}$ & $3,2000 \mathrm{w} /(\mathrm{m} \cdot \mathrm{k})$ \\
\hline Calor Específico & $0,8370 \mathrm{~J} /\left(\mathrm{G} \cdot{ }^{\circ} \mathrm{C}\right)$ & $\begin{array}{ll}\text { Coeficiente de } \\
\text { Poisson }\end{array}$ & 0,25 & Calor Específico & $0,7100 \mathrm{~J} /\left(\mathrm{G} \cdot{ }^{\circ} \mathrm{C}\right)$ \\
\hline Densidade & $1.730,00 \mathrm{~kg} / \mathrm{m}^{3}$ & Densidade & $\begin{array}{l}2.150,00 \\
\mathrm{~kg} / \mathrm{m}^{3}\end{array}$ & Emissividade & 0,90 \\
\hline & & $\begin{array}{l}\text { Resistência } \\
\text { Compressão }\end{array}$ & $77,0 \mathrm{MPa}$ & Porosidade & 0,10 \\
\hline
\end{tabular}

\section{Resultados e Discussões}

Os valores das temperaturas obtidas da parte externa da estrutura no mês de janeiro de 2020 estão apresentados na Quadro 2. O mês de janeiro compreende o inverno e época de chuvas na região, devido a pandemia, não foi possivel realizar as medições no período de julho a setembro, que compreende o período quente.

Quadro 2-Temperaturas Medidas in loco da Catedral Nossa Senhora das Mercês.

\begin{tabular}{|c|c|c|c|c|}
\hline \multicolumn{5}{|c|}{ Paredes - Catedral Nossa Senhora das Mercês } \\
\hline $27 / 01 / 2020$ & \multicolumn{4}{|c|}{ Vista Oeste } \\
\hline Temperaturas & $07: 30-08: 30 \mathrm{~h}$ & $11: 30-12: 30 \mathrm{~h}$ & $17: 30-18: 30 \mathrm{~h}$ & Média do Dia \\
\hline Maior & $23^{\circ} \mathrm{C}$ & $33^{\circ} \mathrm{C}$ & $29^{\circ} \mathrm{C}$ & \multirow{2}{*}{$28^{\circ} \mathrm{C}$} \\
\hline Menor & $22^{\circ} \mathrm{C}$ & $32^{\circ} \mathrm{C}$ & $27^{\circ} \mathrm{C}$ & \\
\hline $27 / 01 / 2020$ & \multicolumn{4}{|c|}{ Vista Leste } \\
\hline Temperaturas & $07: 30-08: 30 \mathrm{~h}$ & $11: 30-12: 30 \mathrm{~h}$ & $17: 30-18: 30 \mathrm{~h}$ & Média do Dia \\
\hline Maior & $24^{\circ} \mathrm{C}$ & $25^{\circ} \mathrm{C}$ & $30^{\circ} \mathrm{C}$ & \multirow{2}{*}{$26^{\circ} \mathrm{C}$} \\
\hline Menor & $23^{\circ} \mathrm{C}$ & $25^{\circ} \mathrm{C}$ & $29^{\circ} \mathrm{C}$ & \\
\hline $31 / 01 / 2020$ & \multicolumn{4}{|c|}{ Vista Oeste } \\
\hline Temperaturas & $07: 30-08: 30 \mathrm{~h}$ & $11: 30-12: 30 \mathrm{~h}$ & $17: 30-18: 30 \mathrm{~h}$ & Média do Dia \\
\hline Maior & $27^{\circ} \mathrm{C}$ & $32{ }^{\circ} \mathrm{C}$ & $33^{\circ} \mathrm{C}$ & \multirow{2}{*}{$31{ }^{\circ} \mathrm{C}$} \\
\hline Menor & $27^{\circ} \mathrm{C}$ & $31^{\circ} \mathrm{C}$ & $33^{\circ} \mathrm{C}$ & \\
\hline $31 / 01 / 2020$ & \multicolumn{4}{|c|}{ Vista Leste } \\
\hline Temperaturas & $07: 30-08: 30 \mathrm{~h}$ & $11: 30-12: 30 \mathrm{~h}$ & $17: 30-18: 30 h$ & Média do Dia \\
\hline Maior & $33^{\circ} \mathrm{C}$ & $38^{\circ} \mathrm{C}$ & $39^{\circ} \mathrm{C}$ & \multirow{2}{*}{$36^{\circ} \mathrm{C}$} \\
\hline Menor & $32^{\circ} \mathrm{C}$ & $36^{\circ} \mathrm{C}$ & $39^{\circ} \mathrm{C}$ & \\
\hline
\end{tabular}

Análise Termo-Higrométricas Da Catedral Nossa Senhora Das Mercês E Suas Implicações Nas Manifestações Patológicas. 
A figura 6 apresenta o projeto arquitetônico da Catedral desenvolvido no software Revit 2020.

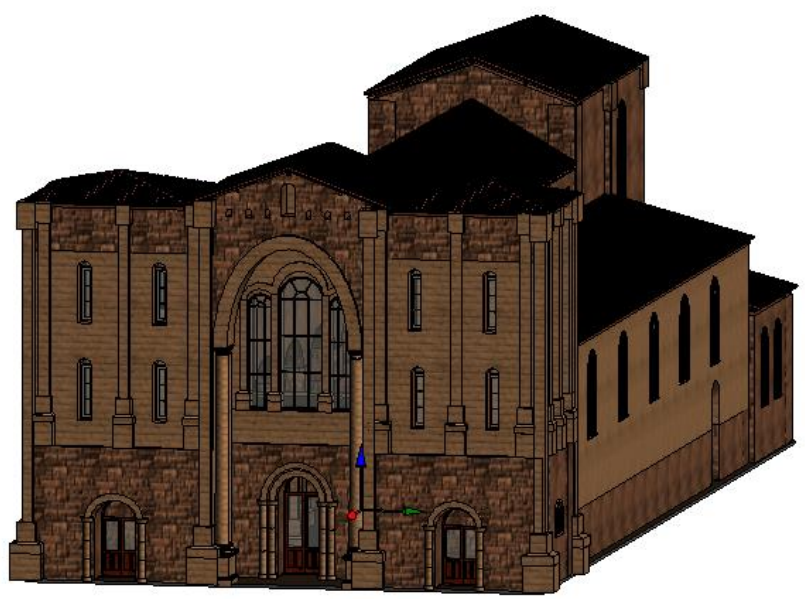

Figura 6 - Projeto arquitetônico da Catedral Nossa Senhora das Mercês

A figura 7a, b e c indicam a posição do sol para os horários de estudo.

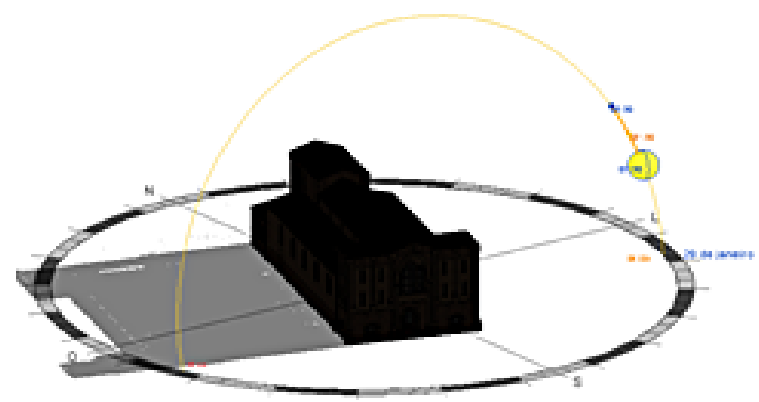

a) Horários 07:30 as 08:30

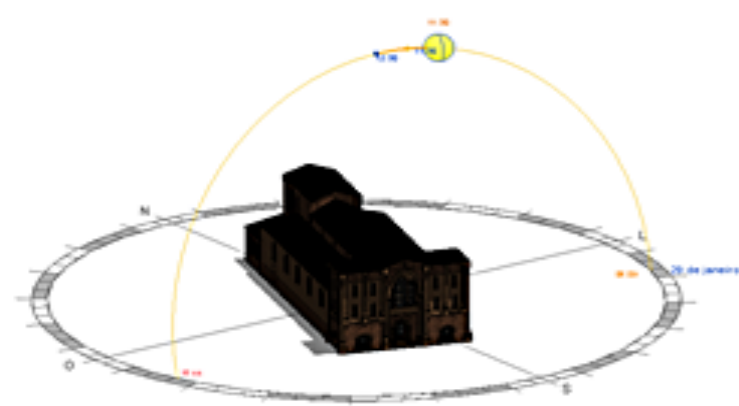

b) Horários $11: 30$ as 12:30

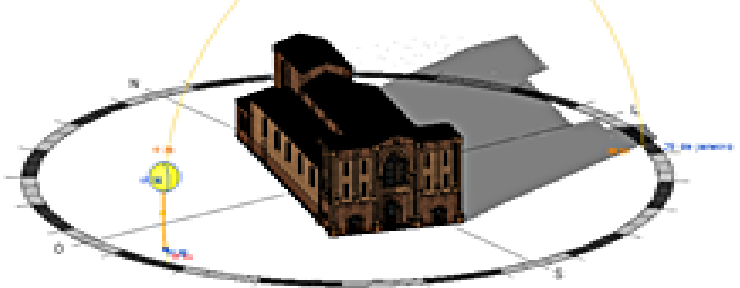

c) Horários $17: 30$ as $18: 30$

Figura 7 - Caminho do Sol na Catedral Nossa Senhora das Mercês

Através do Green Building Studio foi obtido um modelo térmico, com a análise pode-se observar as áreas onde foi obtido maior concentração de umidade e de calor na estrutura. Ao estudar as manifestações patológicas já encontradas na estrutura foi possível relacioná-las com a concentração de calor e de umidade. As figuras $8 \mathrm{a}, \mathrm{b}, \mathrm{c}, \mathrm{d}$ e $\mathrm{f}$ apresentam a análise solar em conjunto com algumas manifestações patológicas encontradas na estrutura.

É possível observar várias manifestações patológicas, diversas dessas ocasionadas pelo excesso de umidade e pela insuficiência solar. Como exemplo, tem-se os limos e bolor oriundos de manchas de umidade causada por algas e fungos.

Ao concluir a análise solar foi possível observar que nos locais em que se obteve essas manifestações patólogicas são as regiões em que existe um valor menor de concentração de calor durante todos os horários da análise, como exemplo, onde existe na estrutura a coloração roxa, também foi possível observar que a localização da catedral possui uma ausência de luz solar. 


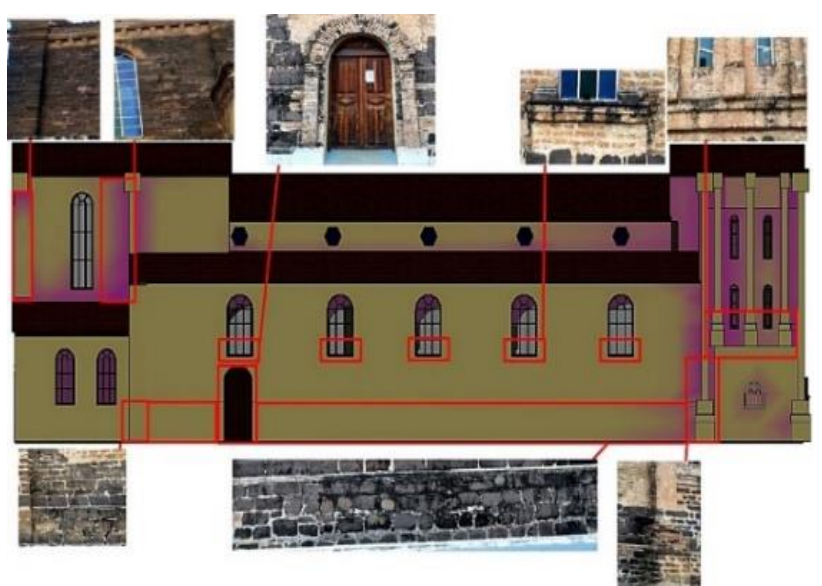

a)



c) Vista Oeste nos horários 11:30 a 12:30



e) Vista Oeste nos horários 17:30 a 18:30

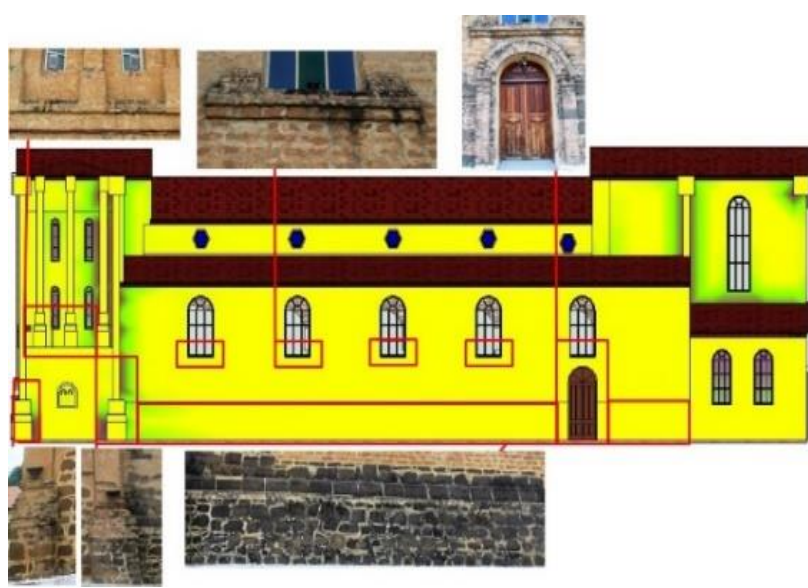

b) Vista Leste nos horários 07:30 a 08:30

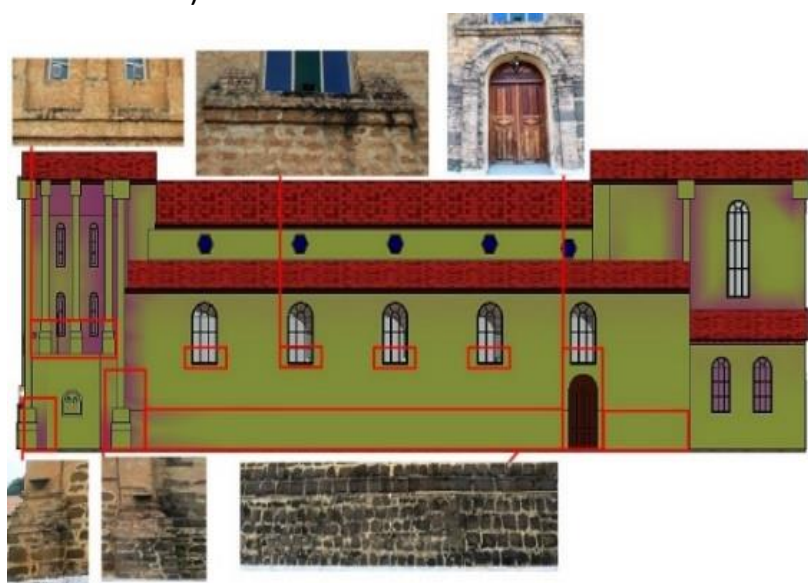

d) Vista Leste nos horários 11:30 a 12:30

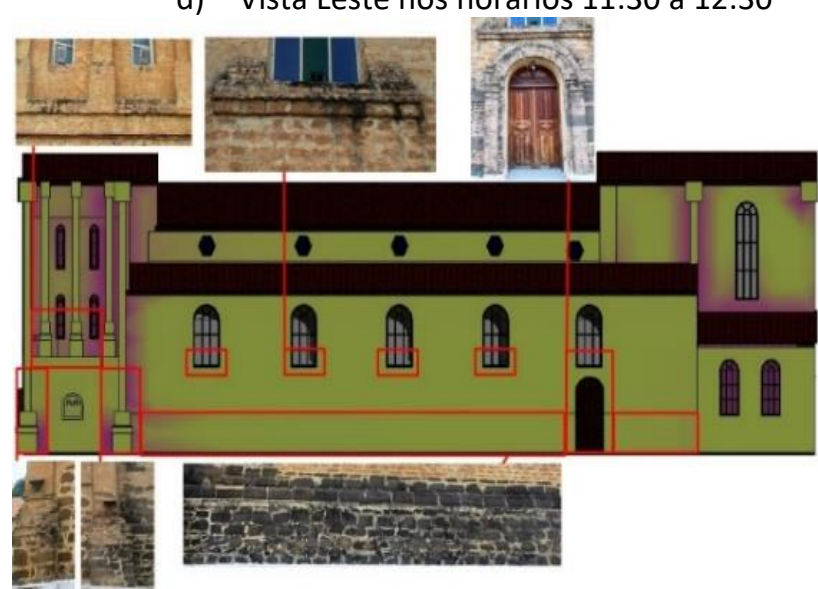

f) Vista Leste nos horários 17:30 a 18:30

Figura 8 - Patologias na Catedral Nossa Senhora das Mercês

A Figura 9 apresenta a variação de temperatura de projeto na Catedral Nossa Senhora das Mercês durante os meses de janeiro a dezembro, obtendo uma margem de erro de $2 \%$ para a mínima e a máxima temperatura de cada mês. Pode-se notar que a variação média de temperatura não é muito discrepante, que existe uma constância em relação a temperatura. Além disso, é possível observar que as menores e maiores temperaturas ocorrem consecutivamente nos meses de junho e setembro. É possível observar que no mês de janeiro as temperaturas de projeto variam de 21 para 34ํ incluindo a margem de erro, enquanto a média diária para as temperaturas verificadas in loco variaram de 26 para $36 \circ \mathrm{C}$. Vale ressaltar que embora o equipamento utilizado in loco não seja o mais avançado e que não foram feitas muitas medições ao longo do mês, é relevante verificar que a diferença de média de temperaturas é relativamente pequena. Outro ponto importante é que os meses de agosto e setembro apresentaram temperatura mais elevadas, esse fato é coerente devido ser considerado os meses mais quentes na região. 


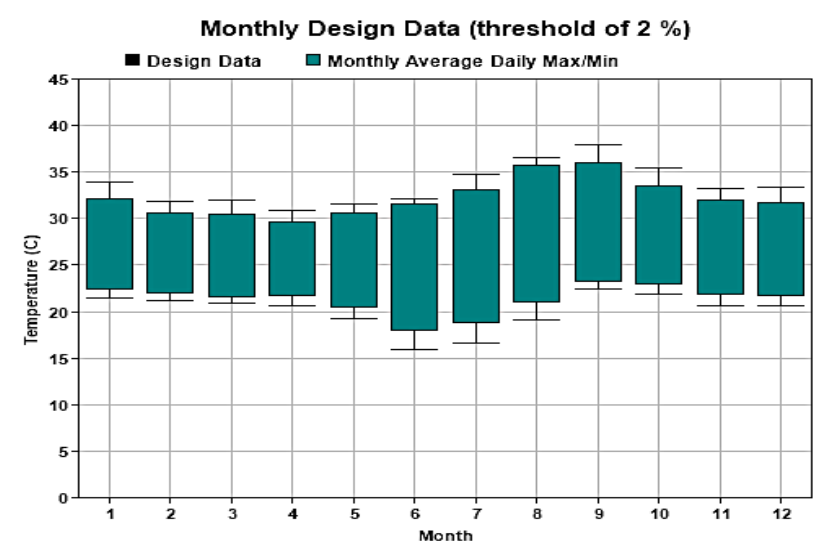

Figura 9 - Variação da temperatura de projeto anualmente

No Figura 10 é apresentado a relação de umidade em distribuição nos meses considerados verão. Nota-se que a umidade permanece relativamente constante ao longo das 24 horas, ocorre pouca variação. Já para o Figura 11 é apresentado a relação de umidade em distribuição nos meses de inverno. É observado que a umidade é relativamente alta e pouquíssima variação, fato que pode corroborar para o surgimento de manifestações patológicas devido à alta umidade.



Figura 10 - Distribuição de frequência de umidade relativa no verão



Figura 11 - Distribuição de frequência de umidade relativa no inverno

A Figura 12 considera a relação anual, pode-se observar que em $55 \%$ do tempo a umidade relativa está entre 90 e $100 \%$, o que explica porque Porto Nacional tem uma sensação térmica elevada, também é considerado um dos fatores que causam manifestações patológicas, por exemplo, quando ocorre o fato da umidade do ar está muito alta existem grandes chances do aparecimento de fungos, mofos e bolores, sendo algumas das anomalias encontrados na Catedral Nossa Senhora das Mercês.

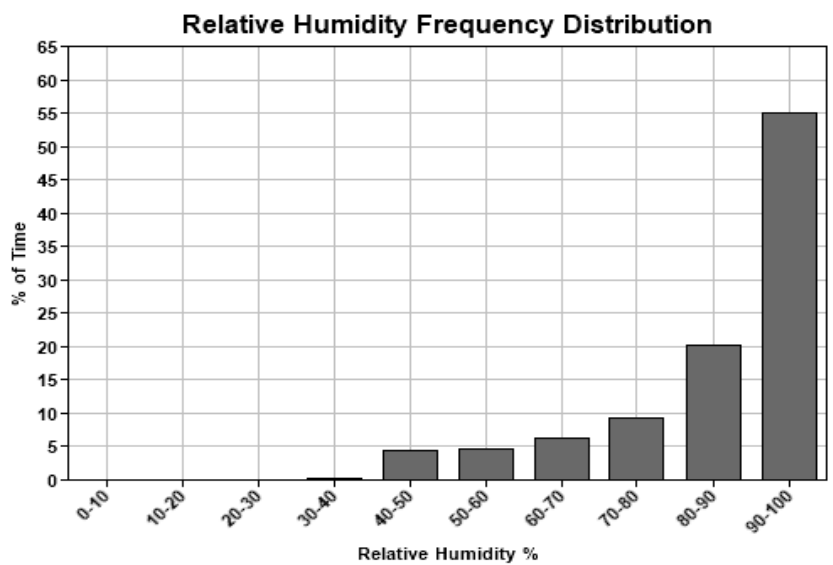

Figura 12- Distribuição de frequência de umidade relativa anual 


\section{Conclusão}

Toda estrutura está sujeita a ações climáticas, no entanto essas ações podem ser prejudiciais para as estruturas compostas por adobe, ocasionando manifestações patológicas. Ao analisar o modelo energético produzido pelo software Revit através do Green Building Studio pode-se concluir que a Catedral Nossa Senhora das Mercês está localizada em uma área que não atinge a carga térmica máxima para o mês em estudo, também é possível verificar que em todos os horários existem insuficiência de luz solar, além da alta umidade relativa do ar, gerando grande parte das manifestações patológicas encontradas, contribuindo assim para a deterioração e comprometendo a estabilidade da estrutura.

Para tanto, faz-se necessário um estudo mais aprofundado comparando as temperaturas obtidas in loco com as temperaturas de projeto para todos os meses do ano, porém devido a pandemia não foi possivel realizar.

\section{Referências Bibliográficas}

BRITO, Jorge de; FLORES, Inês. Paredes De Alvenaria De Pedra Natural. Instituto Superior Técnico Cadeira de Construção de Edifícios. 2003.

DORE, Conor; MURPHY, Maurice. Integration of historic building information modeling (HBIM) and 3D GIS for recording and managing cultural heritage sites. In: INTERNATIONAL CONFERENCE ON VIRTUAL SYSTEMS AND MULTIMEDIA: VIRTUAL SYSTEMS IN THE INFORMATION SOCIETY, 18., 2012, Milan.

IPHAN. Catedral Nossa Senhora das Mercês de Porto Nacional (TO) receberá ações de restauração. IPHAN TOCANTINS, 11 de outubro de 2018.

MANDUCA, Talles. Tombamento do Centro Histórico de Porto Nacional. Porto Nacional. 2007.

OLIVEIRA, Maria de Fátima. Um Porto no Sertão: Cultura e cotidiano em Porto Nacional 1880/1910. 1997. 177 f. Dissertação (Mestrado) - Curso de História, Universidade Federal de Goiás, Goiânia, 1997. Cap. 5.

PEREIRA, Daniel Augusto de Moura et al. PROJETO DE UMA BIOALVENARIA DE VEDAÇÃO A PARTIR DE TERRA CRUA: O CASO DO TIJOLO DE ADOBE. Revista Saúde e Ciência, p.64-75, dez. 2014.

PEREIRA, Emmanoelle Santos. DETERMINAÇÃO DAS PROPRIEDADES TÉRMICAS DAS ROCHAS DO EMBASAMENTO ADJACENTE A BACIA DO RECÔNCAVO. 2008. 61 f. TCC (Graduação) - Curso de Geofísica, Departamento de Geologia e Geofísica Aplicada do Instituto de Geociências da Universidade Federal da Bahia, Universidade Federal da Bahia Instituto de Geociências, Salvador - Bahia, 2008. Cap. 1.

PISANI, Maria Augusta Justi. Taipas: A Arquitetura De Terra. EPUSP - Escola Politécnica da Universidade de São Paulo. São Paulo. 2004.

SOUZA, Gabriela Trichês de. Construção, Conforto Ambiental e Uso Racional de Energia: utilização de imagens em infravermelho para análise térmica de componentes construtivos. 2010. 27 f. TCC (Doutorado) - Curso de Engenharia Civil, Programa Institucional de Bolsas de Iniciação Científica Pibic/cnpq - Bip/ufsc 2009/2010, Universidade Federal de Santa Catarina Centro Tecnológico Departamento de Engenharia Civil, Florianópolis, 2010.

TAGOMORI, Andreia Tiemi; CAVAlLARO, Fernanda. Construção em TIJOLO DE ADOBE. 2011. 12 f. TCC (Graduação) - Curso de Arquitetura, Aut 221 - Arquitetura, Ambiente e Desenvolvimento Sustentável, Universidade de São Paulo - Fau Usp, São Paulo, 2011. Cap. 1.

VALLEJO, L. I. G.; FERRER, M.; ORTUÑO, L.; OTEO, C. Engenheira geológica. Madrid: Prentice Hall, 2002.

VARUM, Humberto et al. CARACTERIZAÇÃO DO COMPORTAMENTO ESTRUTURAL DE PAREDES DE ALVENARIA DE ADOBE. Revista da Associação Portuguesa de Análise Experimental de Tensões, Portugal, v. 15, n. 10, p.1-10, 2008.

VENDRAME, Luis Gabriel Viana. OTIMIZAÇÃO ENERGÉTICA NUM SUPERMERCADO UTILIZANDO O REVIT ${ }^{\circledR}$ E ESTRATÉGIAS DE DAYLIGHTING - SOLUÇÕES PASSIVAS E ATIVAS .2017.

ZINGANOI, André Cezar; KOPPEIL, Jair Carlos; COSTA, João Felipe C.I.. Pilar-barreira entre painéis de lavra para a mina de carvão. Rem: Revista Escola de Minas, Ouro Preto, v. 60, n. 1, p. 1-11, 01 dez. 2006. 